\title{
Aspectos Germinativos de Capim-Camalote (Rottboellia cochinchinensis) ${ }^{1}$
}

\author{
Germination Aspects of Itchgrass (Rottboellia cochinchinensis)
}

\author{
SILVA, C.E.B. ${ }^{2}$, PARREIRA, M.C. ${ }^{3}$, ALVES, P.L.C.A. ${ }^{4}$ e PAVANI, M.C.M.D. ${ }^{4}$
}

\begin{abstract}
RESUMO - O capim-camalote (Rottboellia cochinchinensis), originário da Índia, é encontrado em várias regiões do mundo, sendo uma espécie temida pelos agricultores devido ao seu dificil controle e avanço crescente. Objetivou-se com este trabalho estudar os fatores que afetam a germinação das sementes dessa espécie. Foram avaliados os métodos de superação de dormência: 1 - escarificação mecânica, 2 - escarificação química, 3 - tratamento pré-semeadura, 4 - tratamento químico, 5 - tratamento hormonal e 6 - sementes não tratadas. Foram estudados os efeitos da temperatura $\left(5,10,15,20,25,30,35\right.$ e $\left.40{ }^{\circ} \mathrm{C}\right)$, do fotoperiodo $(6,8,10,12$, 14 e 16 horas de luz), da qualidade da luz incidente (branca, vermelha, vermelha distante, amarela, verde, azul e ausência de luz), da disponibilidade de água $(0,0,-0,2,-0,3,-0,4,-0,5$, $-0,6,-1,2$ e -2,4 MPa) e da viabilidade de suas sementes quando armazenadas sob condições de câmara fria e seca e sob condições naturais. Todos os ensaios foram conduzidos por 30 dias em câmara de germinação, com os tratamentos arranjados em delineamento experimental inteiramente casualizado, em quatro repetições. Verificou-se que as sementes apresentaram elevado indice de germinação, praticamente não apresentaram dormência e não se mostraram fotoblásticas. A disponibilidade de água foi indispensável para a germinação, com temperatura ideal de $25^{\circ} \mathrm{C}$. As sementes recém-coletadas são inviáveis para o estudo da germinação, apresentando redução na germinação quando armazenadas sob condição de câmara fria e seca.
\end{abstract}

Palavras-chave: germinação, biologia, emergência, planta daninha.

\begin{abstract}
Itchgrass (Rottboellia cochinchinensis), is native to India and it is found in several regions of the world. It is feared by farmers because of its difficult control and progress. The aim of this work was to study the factors that affect the germination of this weed's seeds. The methods of overcoming dormancy evaluated were: 1 - mechanical scarification, 2 - chemical scarification, 3 -treatment pre-sowing, 4 - chemical treatment, 5 - hormonal treatment, 6 - untreated seeds. The effects of temperature $\left(5,10,15,20,25,30,35\right.$ and $\left.40^{\circ} \mathrm{C}\right)$, photoperiod $(6,8,10,12,14$ and 16 hours of light), the quality of light (white, red, red bell, yellow, green, blue and absence of light), availability of water $(0.0,-0.2,-0.3,-0.4,-0.5,-0,6,-1.2,-2.4 \mathrm{MPa})$, viability of its seeds when stored under cold, dry and natural conditions were studied. All bioassays were carried out in camera for thirty germination days, with the treatments arranged in a completely randomized design in four repetitions. The seeds had high germination index under our climatic conditions, without dormancy and were not photoblastic. The water deficit from water availability is essential forgermination, with optimum temperature of $25^{\circ} \mathrm{C}$. The newly-collected seeds are not viable forthe germination study, presenting reduction in germination when stored under cold and dry conditions, showing that cold may be an agent of dormancy induction.
\end{abstract}

Keywords: germination, biology, emergence, weed.

1 Recebido para publicação em 12.2.2008 e na forma revisada em 5.6.2009.

2 Engo-Agr ${ }^{\circ}$, Dep. de Biologia Aplicada à Agronomia, Laboratório de Biologia e Manejo de Plantas Daninhas - FCAV/UNESP, Via de acesso Prof. Paulo Donato Castelhane, s/n, 14884-900 Jaboticabal-SP, ${ }^{3}$ Eng ${ }^{a}-A g r a \underline{a}$, Mestranda em Produção Vegetal, Laboratório de Biologia e Manejo de Plantas Daninhas - FCAV/UNESP, <mariana.parreira@posgrad.fcav.unesp.br>; ${ }^{4}$ Professor Associado do Dep. de Biologia Aplicada à Agronomia, Laboratório de Biologia e Manejo de Plantas Daninhas - FCAV/UNESP, <plalves@fcav.unesp.br >,<mcarmo@fcav.unesp.br>.

Planta Daninha, Viçosa-MG, v. 27, n. 2, p. 273-281, 2009 


\section{INTRODUÇÃO}

Rottboellia cochinchinensis, pertencente à familia Poaceae (Gramineae), conhecida vulgarmente na língua inglesa por itchgrass e no Brasil por capim-camalote, é temida pelos agricultores de todo o mundo, sobretudo pelo seu poder de se dispersar, invadindo novas áreas, recebendo denominação de "caminhadora" em muitos países tropicais da América (Alloub et al., 2005). Quando presente, além de interferir diretamente, dificulta e encarece as práticas culturais e de manejo de diversas culturas (Bridgemohan et al., 1992). Os trabalhadores se recusam a entrar nos campos infestados, devido aos seus tricomas simples, pluricelulares silicosos (joçal), que, em contato com a pele, penetram como agulhas de vidro, quebram-se e causam reações alérgicas (Arévalo \& Bertoncini, 1992). De acordo com Bianco et al. (2004), o acúmulo total dos macronutrientes é crescente ao longo do ciclo de desenvolvimento da planta de capim-camalote, atingindo seu acúmulo máximo principalmente antes do florescimento, demonstrando assim seu potencial extrativista e justificando a preocupação com o seu controle, conforme realçado por Freitas et al. (1990), que obtiveram o controle de plantas adultas de $R$. cochinchinensis somente com sulfonilureias, enquanto no controle com a capina manual foi observado alto índice de reinfestação na área.

Segundo Holm et al. (1977), o capim-camalote é originário da Índia, de onde foi dispersado pelo homem para mais de 28 países, mais de 18 culturas, como cana-de-açúcar, arroz, feijão, soja, algodão, amendoim e milho. Ocorre maior problema na faixa de latitude compreendida entre $23^{\circ} \mathrm{N}$ e $23^{\circ} \mathrm{S}$; fora dessa faixa, causa problemas mais intensamente na Austrália e nos Estados Unidos, onde pode atingir de 75 a $100 \%$ do seu potencial de crescimento (Patterson et al., 1979). Apenas na América Central e Caribe é estimado que o capim-camalote infeste mais de 3,5 milhões de hectares (FAO, 1992). Também é considerada uma importante planta daninha no oeste da África (Chikoye et al., 2000). Estima-se que o capim-camalote tenha entrado no Brasil no final da década de 1950, infestando sementes de arroz, provavelmente de origem colombiana (Deuber, 1992). Segundo Freitas et al. (2004), foi introduzido recentemente na região do Rio de Janeiro e infesta culturas anuais e perenes.

Muito vigorosa e prolífica, uma única planta é capaz de emitir até 100 perfilhos e produzir mais de 16.000 sementes (Hall \& Patterson 1992; Smith et al., 2001). De forma similar, Tucuch (1991) estimou a produção de sementes em até 6.500 sementes $\mathrm{m}^{-2}$ sob condições de convivio com a cultura do milho em Campeche, México. Contudo, a contribuição das sementes para o banco de sementes é muito menor do que pode ser estimado pela produção por planta. Uma grande quantidade de sementes é perdida antes do início da safra seguinte. Em um campo altamente infestado na Costa Rica, por exemplo, a contagem de sementes no início da safra forneceu a média de 324 sementes $\mathrm{m}^{-2}$ (Smith et al., 2001).

Relatos de dormência de suas sementes e de padrões de germinação variam substancialmente através do mundo (Holm et al., 1977). Bridgemohan et al. (1991) determinaram que, na cultura do milho, de 40 a $60 \%$ das sementes podem persistir no solo após um ano do cultivo, com a dormência inata e induzida contribuindo com 8,5 e 35\%, respectivamente. Na Costa Rica, Rojas et al. (1994) demonstraram que algumas sementes permaneceram viáveis após 18 meses de enterrio no solo. Segundo Sharma \& Zelaya (1986) e Lorenzi (2000), as sementes de capim-camalote podem ficar dormentes no solo por até quatro anos. Sementes na superficie ou enterradas a 5 e $10 \mathrm{~cm}$ de profundidade perdem a persistência substancialmente; a $20 \mathrm{~cm}$ de profundidade, menos de $10 \%$ das sementes continuam viáveis. Bridgemohan et al. (1991) demonstraram que o cultivo aumenta a taxa de depleção no banco de sementes em $32 \%$ ao ano.

Regimes de temperatura, de luz e tratamentos químicos, entre os quais a aplicação de nitrato de potássio, são fatores que afetam a germinação de sementes (Popinigis, 1985); além disso, podem revelar diversos mecanismos de dormência, exigindo técnicas específicas para sua superação (Khan, 1977). Para Etejere \& Ajibola (1991), a germinação das sementes de capim-camalote pode ser aumentada pela exposição ao calor seco $\left(80^{\circ} \mathrm{C}\right)$ por um minuto, em concentrações variando entre 100 
e 500 ppm de ethephon, dos seguintes compostos: IAA, tioureia, nitrato de potássio ou tiosulfato de sódio por 24 horas, ou, ainda, imersão em água corrente, ácido sulfúrico ou clorídrico ou nítrico por 1 a 25 minutos.

Considerando que o capim-camalote está infestando lavouras no Brasil e que apresenta elevada agressividade associada a um difícil controle, particularmente na cultura da canade-açúcar, qualquer conhecimento adicional sobre a biologia dessa espécie proporcionará maiores subsídios para o seu manejo nas nossas condições.

Com este trabalho, objetivou-se estudar a ocorrência de dormência nas sementes de capim-camalote e o efeito da temperatura, fotoperíodo, qualidade da luz, disponibilidade de água e condições de armazenamento sobre a germinação das sementes dessa espécie de planta daninha.

\section{MATERIAL E MÉTODOS}

As sementes de Rottboellia cochinchinensis foram coletadas de dois modos: por varredura e na planta (sem contato com o solo), nos municípios de Aramina e Dumont-SP. Na sequência, foi determinada a porcentagem e o índice de velocidade de germinação (IVG), de acordo com Putnam \& Tang (1986), a viabilidade (teste topográfico de tetrazólio) e a dormência natural de sementes. Posteriormente, as sementes foram separadas em dois lotes, sendo um armazenado em câmara fria e seca $\left(7^{\circ} \mathrm{C}\right.$, $\mathrm{UR}_{\mathrm{ar}}<20 \%$ ) e outro sob condições naturais, de laboratório.

Com as sementes armazenadas sob condições naturais, foram testados os métodos de superação de dormência: 1 - escarificação mecânica - atrito em lixa d' água por 20 segundos; 2 - escarificação química - imersão em ácido sulfúrico concentrado por 1, 2, 4, 8, 16 e 32 minutos; 3 - tratamento pré-semeadura imersão em água corrente pelos mesmos períodos de tempo; 4- tratamento químico imersão em solução de nitrato de potássio $1 \mathrm{M}$ pelos mesmos períodos de tempo; 5 - tratamento hormonal - imersão em solução de giberelina pelos mesmos períodos de tempo; e 6 - sementes não tratadas. Os tratamentos foram arranjados em delineamento experimental inteiramente casualizado com quatro repetições, sendo a parcela experimental constituída por placas tipo Gerbox com 50 sementes. Os ensaios foram conduzidos por 30 dias em câmara de germinação $\left(30 / 15{ }^{\circ} \mathrm{C}\right)$ para um fotoperíodo de 14/ 10 horas.

Após esses ensaios, para esse mesmo lote de sementes, foram determinados os efeitos da temperatura $(5,10,15,20,25,30,35$ e $40^{\circ} \mathrm{C}$ ), da qualidade da luz incidente (branca, vermelha, vermelha distante, amarela, verde, azul e ausência de luz), da disponibilidade de água (estresse simulado por soluções de Polietilenoglicol - PEG 6000 - ajustadas para potenciais osmóticos de $0,0,-0,2,-0,3,-0,4$, $0,5,-0,6,-1,2$ e $-2,4 \mathrm{MPa}$ ), da viabilidade de suas sementes quando armazenadas em condições de câmara fria e seca e em condições naturais e do fotoperíodo $(6,8,10,12,14$ e 16 horas de luz). Foi realizado um ensaio complementar, avaliando o efeito da coleta das sementes (na planta e por varredura) sobre suas características germinativas. Para estes ensaios, o delineamento experimental e as condições de condução e avaliações foram semelhantes aos dos ensaios anteriores.

Os dados obtidos foram submetidos à análise de variância pelo teste $\mathrm{F}$ e, para comparação das médias, utilizou-se o teste de Tukey a 5\% de probabilidade. Quando pertinente, os dados foram submetidos também à analise de regressão.

\section{RESULTADOS}

As sementes recém-colhidas apresentaram um período total de germinação de 15 dias, e a maioria das sementes germinou nos primeiros seis dias. A porcentagem de germinação foi de, em média, 51,4\%, com o IVG de 1.429 , pelo fato de a maioria das sementes germinar até o décimo dia. Entre as sementes que não germinaram, 14,4\% mostraram-se viáveis pelo teste topográfico de tetrazólio; somadas a $51,4 \%$ germinadas, totalizaram-se $65,8 \%$ de sementes potencialmente viáveis.

Foi constatado que com a escarificação mecânica a germinação média foi de 30,5\%. Entre as sementes que não germinaram, $13,5 \%$ mostraram-se viáveis (Tabela 1 ). Esses resultados foram inferiores ao observado no teste de germinação inicial, indicando que esse tratamento foi ineficiente para aumentar 
Tabela 1 - Porcentagem de germinação (\%G), índice de velocidade de germinação (IVG), viabilidade $(\% \mathrm{~V})$ e inviabilidade $(\% \mathrm{I})$ de sementes de $R$. cochinchinensis, quanto ao método de superação de dormência por escarificação mecânica (atrito em lixa d'água)

\begin{tabular}{|l|r|r|r|r|}
\hline \multicolumn{1}{|c|}{ Repetição } & \multicolumn{1}{c|}{$\% \mathrm{G}$} & \multicolumn{1}{|c|}{ IVG } & $\% \mathrm{~V}^{\underline{1}}$ & $\% \mathrm{I}$ \\
\hline Testemunha & 35,9 & 388,0 & 20,3 & 26,7 \\
\hline Média & 30,5 & 303,0 & 13,5 & 56,0 \\
\hline Desvio-Padrão & 3,6 & 58,7 & 2,7 & 3,1 \\
\hline
\end{tabular}

1/ Teste do tetrazólio (sementes remanescentes)

as porcentagens de germinação. Segundo Bridgemohan et al. (1991), a maior porcentagem de sementes que persistem no solo se deve à dormência inata; o atrito resultante do preparo do solo resulta em novo fluxo de emergência, diminuindo o número de sementes no banco. Com outras plantas daninhas, a escarificação mecânica causa aumento na germinação, como, por exemplo, observado no trabalho de Salvador et al. (2007), que, ao submeterem sementes de Ipomoea nil e Euphorbia heterophylla ao tratamento com lixa abrasiva, conseguiram resultados positivos para a superação de dormência.

Com relação à escarificação química, não foi observada nenhuma semente de capimcamalote germinada. Toledo et al. (1995) observaram que sementes de Panicum maximum não apresentaram resultado positivo quando tratadas com ácido sulfúrico, resultando em 100\% das sementes mortas. Esses dados contradizem os de Schimid (1979) e Usberti (1981), pois ambos relataram ação benéfica do tratamento sobre a germinação de $P$. maximum; Loubser $\&$ Rubert (1992) obtiveram resultados favoráveis em ensaios realizados com $P$. coloratum. Por outro lado, Meschede et al. (2004), utilizando tratamento de acido sulfúrico concentrado em braquiária cultivar Marandu, verificaram morte de todas as sementes testadas.

Quanto ao tratamento de pré-semeadura, a maior porcentagem e velocidade de germinação ocorreu com um minuto de embebição, porém não diferindo da testemunha (Tabela 2). Períodos de imersão superiores a este reduziram esses parâmetros, sem, contudo, afetar a viabilidade das sementes.

No tratamento químico de imersão por diferentes tempos em solução de nitrato de potássio a $1 \mathrm{M}$, a porcentagem de germinação, o IVG e a viabilidade das sementes foram idênticos aos da testemunha (Tabela 3). Esses resultados demonstram que esse método foi ineficiente para superar a dormência das sementes de capim-camalote.

Tabela 2 - Valores médios de porcentagem de germinação (\%G), índice de velocidade de germinação (IVG), viabilidade $(\% \mathrm{~V})$ e inviabilidade (\%) de sementes de $R$. cochinchinensis, resultantes do método de superação de dormência por tratamento de pré-semeadura (tempos de imersão em água)

\begin{tabular}{|c|c|c|c|c|}
\hline Tratamento & $\% \mathrm{G}$ & IVG & $\% \mathrm{~V}^{\mathrm{1} /}$ & $\% \mathrm{I}$ \\
\hline Testemunha & $34,94 \mathrm{~A}$ & $388 \mathrm{~A}$ & $20,32 \mathrm{AB}$ & $26,73 \mathrm{~B}$ \\
\hline $1^{\prime}$ & $38,86 \mathrm{~A}$ & $496 \mathrm{~A}$ & $14,40 \mathrm{~B}$ & $28,25 \mathrm{AB}$ \\
\hline $2^{\prime}$ & $24,31 \mathrm{CD}$ & $166 \mathrm{C}$ & $22,12 \mathrm{~A}$ & $31,45 \mathrm{AB}$ \\
\hline $4^{\prime}$ & $30,15 \mathrm{BC}$ & $231 \mathrm{BC}$ & $16,83 \mathrm{AB}$ & $30,09 \mathrm{AB}$ \\
\hline $8^{\prime}$ & $21,49 \mathrm{D}$ & $150 \mathrm{C}$ & $22,69 \mathrm{~A}$ & $32,05 \mathrm{AB}$ \\
\hline $16^{\prime}$ & $21,25 \mathrm{D}$ & $137 \mathrm{C}$ & $20,55 \mathrm{AB}$ & $33,64 \mathrm{~A}$ \\
\hline 32 & $23,16 \mathrm{D}$ & $180 \mathrm{C}$ & $21,66 \mathrm{~A}$ & $32,23 \mathrm{AB}$ \\
\hline F trat. & $17,66 * *$ & $9,64 * *$ & $3,68 *$ & $3,93 * *$ \\
\hline DMS & 7,87 & -92 & 15,22 & 5,64 \\
\hline CV $(\%)$ & 12,28 & 38,6 & 6,98 & 8,01 \\
\hline
\end{tabular}

Valores transformados em arc sen $V_{\mathrm{X}}$

1/ Teste do tetrazólio (sementes remanescentes).

Médias seguidas de mesma letra não diferem entre si a $5 \%$ de probabilidade pelo teste de Tukey; * significativo a $5 \%$ de probabilidade pelo teste $\mathrm{F}$; $\mathrm{e}^{* *}$ significativo a $1 \%$ de probabilidade pelo teste $\mathrm{F}$.

Tabela 3 - Valores médios de porcentagem de germinação (\%G), índice de velocidade de germinação (IVG), viabilidade $(\% \mathrm{~V})$ e inviabilidade (\%) de sementes de $R$. cochinchinensis, resultantes do método de superação de dormência por tratamento químico (tempos de imersão em solução $1 \mathrm{M}$ de $\mathrm{KNO}_{3}$ )

\begin{tabular}{|c|c|c|c|c|}
\hline $\mathrm{KNO}_{3} 1 \mathrm{M}$ & $\% \mathrm{G}$ & $\mathrm{IVG}$ & $\% \mathrm{~V}^{\mathrm{1} /}$ & $\% \mathrm{I}$ \\
\hline Testemunha & $34,94 \mathrm{~A}$ & $388 \mathrm{~A}$ & $20,32 \mathrm{AB}$ & $26,73 \mathrm{~B}$ \\
\hline $1^{\prime}$ & $29,59 \mathrm{~A}$ & $279 \mathrm{~A}$ & $12,66 \mathrm{~A}$ & $35,93 \mathrm{AB}$ \\
\hline $2^{\prime}$ & $28,69 \mathrm{~A}$ & $303 \mathrm{~A}$ & $11,54 \mathrm{~A}$ & $34,09 \mathrm{AB}$ \\
\hline $4^{\prime}$ & $28,45 \mathrm{~A}$ & $302 \mathrm{~A}$ & $9,83 \mathrm{~A}$ & $37,75 \mathrm{~A}$ \\
\hline $8^{\prime}$ & $32,21 \mathrm{~A}$ & $358 \mathrm{~A}$ & $13,98 \mathrm{~A}$ & $32,26 \mathrm{AB}$ \\
\hline $16^{\prime}$ & $26,09 \mathrm{~A}$ & $246 \mathrm{~A}$ & $16,40 \mathrm{~A}$ & $34,14 \mathrm{AB}$ \\
\hline $32^{\prime}$ & 28,00 & $278 \mathrm{~A}$ & $14,20 \mathrm{~A}$ & $35,06 \mathrm{AB}$ \\
\hline F trat. & $2,16^{\mathrm{NS}}$ & $0,60^{\mathrm{NS}}$ & $2,28^{\mathrm{NS}}$ & $4,27 *$ \\
\hline$-\mathrm{DMS}$ & 10,90 & 221 & 22,67 & 9,38 \\
\hline CV(\%) & 14,84 & 33,03 & 12,70 & 7,01 \\
\hline
\end{tabular}

Valores transformados em arc sen $\sqrt{x}_{\mathrm{x}}$.

1/ Teste do tetrazólio (sementes remanescentes).

Médias seguidas de mesma letra não diferem entre si a 5\% de probabilidade pelo teste de Tukey; $*$ significativo a $5 \%$ de probabilidade pelo teste $\mathrm{F}$; e ${ }^{\mathrm{NS}}$ não-significativo pelo teste $\mathrm{F}$. 
Meschede et al. (2004) observaram que $\mathrm{KNO}_{3}$ a $2 \%$ aumentou significativamente a porcentagem de plântulas normais no teste de germinação em sementes de capim-braquiária, em relação à testemunha. Martins \& Silva (2001), ao utilizarem $\mathrm{KNO}_{3}$ a $2 \%$ nas sementes de $B$. brizanta cultivar Marandu, observaram reduções significativas na taxa de dormência em comparação com a testemunha. Contudo, os tratamentos com $\mathrm{KNO}_{3}$ e ácido giberélico não se mostraram eficientes na superação da dormência de sementes de Paspalum paniculatum (Lula et al., 2000).

O efeito positivo da adição de solução aquosa de nitrato de potássio ao substrato de germinação de sementes é frequentemente relatado na literatura. Toole et al. (1956) salientaram que nitratos são um dos principais agentes de superação de dormência em numerosas espécies. Mais recentemente, Gupta (2002), estudando diversas espécies de Ocimum, conseguiu a superação da dormência das sementes pela utilização de soluções de nitrato de potássio. Na espécie Plantago major, Saruhan et al. (2002) aumentaram a germinação ao embeber as sementes em solução de nitrato de potássio a $1 \mathrm{mM}$ ou $10 \mathrm{mM}$. Roberts (1972) afirmou que o efeito isolado do íon nitrato pode ser pouco significativo; no entanto, em interação com luz e, mais ainda, com temperaturas alternadas, o efeito estimulador aumenta fortemente, chegando a mencionar casos em que o nitrato pode até substituir a necessidade de luz.

No tratamento hormonal, em todos os períodos estudados, as sementes de capimcamalote apresentaram tendência de menores porcentagens de germinação, IVG e viabilidade quando comparadas com as da testemunha, principalmente nos tempos de embebição de um a dois minutos (Tabela 4). Câmara \& Stacciarini-Seraphin (2002) submeteram sementes de Brachiaria brizantha ao tratamento hormonal com ácido giberélico e não obtiveram acréscimo na porcentagem de germinação. No entanto, Dantas et al. (2001) aplicaram acido giberélico em baixas concentrações em sementes de Brachiaria plantaginea e obtiveram resultados positivos na germinação das sementes. Pelos resultados, pode-se inferir que a concentração endógena de ácido giberélico nas sementes de capim-camalote é suficiente para garantir a germinação destas.
Quando as porcentagens médias obtidas pelos diferentes métodos de quebra de dormência (independentemente do tempo de imposição dos tratamentos) foram comparadas às da testemunha, verificou-se que os valores da testemunha foram maiores; apenas a escarificação mecânica proporcionou germinação semelhante à da testemunha (Tabela 5). Dessa forma, nenhum dos métodos de superação de dormência testados se mostrou promissor para aumentar a germinação de $R$. cochinchinensis.

Tabela 4 - Valores médios de porcentagem de germinação (\%G), índice de velocidade de germinação (IVG), viabilidade $(\% \mathrm{~V})$ e inviabilidade (\%I) de sementes de $R$. exaltata, resultantes do método de superação de dormência por tratamento hormonal (tempos de imersão de solução giberelina $1 \mathrm{mM}$ )

\begin{tabular}{|c|c|c|c|c|}
\hline $\begin{array}{c}\text { Giberelina } \\
(\mathrm{mM})\end{array}$ & $\% \mathrm{G}$ & IVG & $\% \mathrm{~V}^{1 /}$ & $\% \mathrm{I}$ \\
\hline Testemunha & $34,94 \mathrm{~A}$ & $388 \mathrm{~A}$ & $20,32 \mathrm{AB}$ & $26,73 \mathrm{~B}$ \\
\hline $1^{\prime}$ & $24,89 \mathrm{~B}$ & $235 \mathrm{AB}$ & $17,36 \mathrm{~A}$ & $33,44 \mathrm{AB}$ \\
\hline $2^{\prime}$ & $23,48 \mathrm{~B}$ & $194 \mathrm{~B}$ & $16,88 \mathrm{~A}$ & $35,06 \mathrm{~A}$ \\
\hline $4^{\prime}$ & $29,98 \mathrm{AB}$ & $316 \mathrm{AB}$ & $12,23 \mathrm{~A}$ & $35,06 \mathrm{~A}$ \\
\hline $8^{\prime}$ & $28,00 \mathrm{AB}$ & $280 \mathrm{AB}$ & $13,75 \mathrm{~A}$ & $32,50 \mathrm{AB}$ \\
\hline $16^{\prime}$ & $32,24 \mathrm{AB}$ & $348 \mathrm{AB}$ & $17,80 \mathrm{~A}$ & $30,98 \mathrm{~A}$ \\
\hline $32^{\prime}$ & $29,82 \mathrm{AB}$ & $340 \mathrm{AB}$ & $15,34 \mathrm{~A}$ & $34,14 \mathrm{~A}$ \\
\hline F trat. & $4,97^{* *}$ & $2,79^{*}$ & 1,11 & $5,53^{*}$ \\
\hline DMS & 8,77 & 174 & 14,28 & 6,95 \\
\hline CV $(\%)$ & 13,07 & 25,6 & 22,18 & 5,37 \\
\hline
\end{tabular}

Valores transformados em arc sen $V_{\mathrm{x}}$

1/ Teste do tetrazólio (sementes remanescentes).

Médias seguidas de mesma letra não diferem entre si a $5 \%$ de probabilidade pelo teste de Tukey; ${ }^{*}$ significativo a $5 \%$ de probabilidade pelo teste $\mathrm{F}$; ${ }^{* *}$ significativo a $1 \%$ de probabilidade pelo teste $F$; e NS não-significativo pelo teste $F$.

Tabela 5 - Valores médios de porcentagem de germinação (\%G) de sementes de $R$. cochinchinensis, referentes aos métodos de superação de dormência

\begin{tabular}{|l|c|}
\hline \multicolumn{1}{|c|}{ Método } & $\% \mathrm{G}^{1 /}$ \\
\hline Testemunha & $35,94 \mathrm{~A}$ \\
\hline Lixa d'água & $33,49 \mathrm{~A}$ \\
\hline $\mathrm{KNO}_{3}-1 \mathrm{M}$ & $29,02 \mathrm{~B}$ \\
\hline Giberelina -1mM & $28,29 \mathrm{~B}$ \\
\hline Emb.água & $27,02 \mathrm{~B}$ \\
\hline $\mathrm{H}_{2} \mathrm{SO}_{4}$ & $0,00 \mathrm{C}$ \\
\hline $\mathrm{F}$ trat. & $77,56^{* *}$ \\
\hline DMS & 4,39 \\
\hline $\mathrm{CV}(\%)$ & 7,62 \\
\hline
\end{tabular}

1/ Valores transformados em arc sen $\sqrt{x}_{\mathrm{x}}$.

Médias seguidas de mesma letra não diferem entre si a $5 \%$ de probabilidade pelo teste de Tukey; e ${ }^{* *}$ significativo a $1 \%$ de probabilidade pelo teste $\mathrm{F}$.

Planta Daninha, Viçosa-MG, v. 27, n. 2, p. 273-281, 2009 
A temperatura é considerada um requerimento para a germinação de sementes (Patterson et al., 1979). Assim, quando as sementes de capim-camalote foram submetidas a diferentes temperaturas, constatou-se que na de $25{ }^{\circ} \mathrm{C}$ se encontrou a maior porcentagem de germinação. Foi observado que em temperaturas inferiores a $10{ }^{\circ} \mathrm{C}$ as sementes se mostraram dormentes, sem nenhuma germinação, enquanto a partir de $30{ }^{\circ} \mathrm{C}$ a porcentagem de germinação decresceu bruscamente, evidenciando, provavelmente, danos fisiológicos às sementes (Tabela 6).

Martins \& Silva (2001) obtiveram redução da taxa de dormência de sementes de $B$. brizanta cultivar Marandu com tratamento térmico de $70{ }^{\circ} \mathrm{C}$ a 10 e 15 horas. Ao utilizar tratamento com $85{ }^{\circ} \mathrm{C}$, observaram redução da dormência e resultados positivos imediatos no desempenho das sementes, mas promovendo deterioração fisiológica destas.

Quando se submeteram as porcentagens de germinação das sementes de capim-camalote à análise de regressão em função das temperaturas testadas ( $\mathrm{T}$ ), foi observado que esta apresentou tendência quadrática $(\% \mathrm{G}=$ $-21,95+4,23^{*} \mathrm{~T}^{2}$ ), com porcentagem máxima de germinação estimada em 31,4 a $24,6{ }^{\circ} \mathrm{C}$.

No meio agrícola, as sementes podem ficar expostas à luz por períodos prolongados, e esta apresenta, na maioria das vezes, uma composição espectral complexa (Ishimine, 1988). No caso do capim-camalote, foi constatado que os diferentes comprimentos de luz testados, ou seja, a ausência deles proporcionada pelos diferentes filtros, não afetaram significativamente a porcentagem e o IVG (Tabela 7). Dessa forma, constatou-se que a luz não foi um fator limitante para a germinação dessa espécie de planta daninha.

Da mesma forma que a luz, a disponibilidade de água é tida como um requerimento para germinação de sementes (Hernández \& Soto, 1990). Assim, quando as sementes foram submetidas a diferentes concentrações de PEG 6000, simulando deficiência hídrica, foi observado que a testemunha apresentou a maior porcentagem de germinação e IVG; à medida que o potencial osmótico foi aumentando, a porcentagem e o indice de velocidade de germinação das sementes diminuíram, tornando-se inexpressiva a germinação em potenciais inferiores a - 0,5 MPa (Tabela 8).

Verificou-se que as sementes coletadas na planta são inviáveis para o estudo de germinação, pois a porcentagem e o indice de velocidade de geminação dessas sementes foram muito inferiores aos obtidos com as sementes coletadas na superfície do solo

Tabela 6 - Porcentagem de germinação (\%G), índice de velocidade de germinação (IVG), viabilidade (\%V) e inviabilidade (\%I) de sementes de $R$. cochinchinensis, quando submetidas a diferentes temperaturas

\begin{tabular}{|c|c|c|c|c|}
\hline $\begin{array}{c}\text { Temperatura } \\
\left({ }^{\circ} \mathrm{C}\right)\end{array}$ & $\% \mathrm{G}$ & $\mathrm{IVG}$ & $\% \mathrm{~V}^{1 /}$ & $\% \mathrm{I}$ \\
\hline 5 & $0,00 \mathrm{D}$ & $0 \mathrm{~B}$ & $46,14 \mathrm{~A}$ & $48,85 \mathrm{AB}$ \\
\hline 10 & $0,00 \mathrm{D}$ & $0 \mathrm{~B}$ & $45,57 \mathrm{~A}$ & $44,42 \mathrm{AB}$ \\
\hline 15 & $33,29 \mathrm{AB}$ & $82 \mathrm{~A}$ & $28,65 \mathrm{~B}$ & $45,00 \mathrm{AB}$ \\
\hline 20 & $35,94 \mathrm{AB}$ & $90 \mathrm{~A}$ & $25,07 \mathrm{~B}$ & $44,42 \mathrm{AB}$ \\
\hline 25 & $37,66 \mathrm{~A}$ & $90 \mathrm{~A}$ & $28,65 \mathrm{~B}$ & $42,70 \mathrm{AB}$ \\
\hline 30 & $26,45 \mathrm{BC}$ & $76 \mathrm{~A}$ & $26,54 \mathrm{~B}$ & $50,77 \mathrm{~A}$ \\
\hline 35 & $22,33 \mathrm{C}$ & $65 \mathrm{~A}$ & $31,11 \mathrm{~B}$ & $47,29 \mathrm{~A}$ \\
\hline 40 & $26,49 \mathrm{BC}$ & $76 \mathrm{~A}$ & $23,54 \mathrm{~B}$ & $32,83 \mathrm{~B}$ \\
\hline $\mathrm{F}$ trat. & $41,29 * *$ & $31,71 * *$ & $20,52 * *$ & $4,49 *$ \\
\hline $\mathrm{DMS}$ & 10,91 & 31,35 & 11,02 & 13,56 \\
\hline $\mathrm{CV}(\%)$ & 20,47 & 22,45 & 8,73 & 7,80 \\
\hline
\end{tabular}

Valores transformados em arc sen $\sqrt{x}_{\mathrm{x}}$.

1/ Teste topográfico do tetrazólio (sementes remanescentes). Médias seguidas de mesma letra não diferem entre si a $5 \%$ de probabilidade pelo teste de Tukey; $*$ significativo a $5 \%$ de probabilidade pelo teste $\mathrm{F}$; $* *$ significativo a $1 \%$ de probabilidade pelo teste $F$; e ${ }^{N S}$ não-significativo pelo teste $F$.

Tabela 7 - Valores médios de porcentagem de germinação (\%G) e índice de velocidade de germinação (IVG) de sementes de $R$. cochinchinensis, resultantes do efeito de diferentes filtros de luz

\begin{tabular}{|l|c|c|}
\hline \multicolumn{1}{|c|}{ Filtro } & $\% \mathrm{G}^{\mathrm{I}^{/}}$ & $\mathrm{IVG}$ \\
\hline Vermelho & $32,40 \mathrm{~A}$ & $374 \mathrm{~A}$ \\
\hline Verde & $32,45 \mathrm{~A}$ & $378 \mathrm{~A}$ \\
\hline Amarelo & $33,16 \mathrm{~A}$ & $395 \mathrm{~A}$ \\
\hline Azul & $30,65 \mathrm{~A}$ & $322 \mathrm{~A}$ \\
\hline Vermelho distante & $25,83 \mathrm{~A}$ & $247 \mathrm{~A}$ \\
\hline Transparente & $32,14 \mathrm{~A}$ & $383 \mathrm{~A}$ \\
\hline Escuro & $28,21 \mathrm{~A}$ & $301 \mathrm{~A}$ \\
\hline F trat. & $2,14^{\mathrm{NS}}$ & $1,911^{\mathrm{NS}}$ \\
\hline DMS & 8,51 & 181 \\
\hline CV(\%) & 12,06 & 23,02 \\
\hline
\end{tabular}

${ }^{1 /}$ Valores transformados em arc sen $\sqrt{x}_{\mathrm{X}}$

Médias seguidas de mesma letra não diferem entre si a $5 \%$ de probabilidade pelo teste de Tukey; $\mathrm{e}^{\mathrm{NS}}$ não-significativo pelo teste $\mathrm{F}$. 
Tabela 8 - Valores médios de porcentagem de germinação (\%G) e índice de velocidade de germinação (IVG) de sementes de $R$. cochinchinensis, resultantes do efeito da disponibilidade de água

\begin{tabular}{|c|c|c|}
\hline $\begin{array}{c}\text { Potencial osmótico } \\
(\mathrm{MPa})\end{array}$ & $\mathrm{oG}^{\mathrm{1}^{-}}$ & $\mathrm{IVG}$ \\
\hline 0 & $41,69 \mathrm{~A}$ & $519 \mathrm{~A}$ \\
\hline$-0,2$ & $27,54 \mathrm{~B}$ & $314 \mathrm{AB}$ \\
\hline$-0,3$ & $27,96 \mathrm{~B}$ & $271 \mathrm{~B}$ \\
\hline$-0,4$ & $27,94 \mathrm{~B}$ & $275 \mathrm{~B}$ \\
\hline$-0,5$ & $8,98 \mathrm{C}$ & $31 \mathrm{C}$ \\
\hline$-0,6$ & $2,03 \mathrm{C}$ & $5 \mathrm{C}$ \\
\hline$-1,2$ & $0,00 \mathrm{C}$ & $0 \mathrm{C}$ \\
\hline$-2,4$ & $0,00 \mathrm{C}$ & $0 \mathrm{C}$ \\
\hline $\mathrm{F}$ trat. & $55,44^{\mathrm{NS}}$ & 18,87 \\
\hline $\mathrm{DMS}$ & $10,-15$ & 210,00 \\
\hline $\mathrm{CV}(\%)$ & 25,5 & 50,82 \\
\hline
\end{tabular}

1/ Valores transformados em arc sen $V_{\mathrm{X}}$

Médias seguidas de mesma letra não diferem entre si a $5 \%$ de probabilidade pelo teste de Tukey; $* *$ significativo a $1 \%$ de probabilidade pelo teste $F$; e ${ }^{\mathrm{NS}}$ não-significativo pelo teste $\mathrm{F}$.

(Tabela 9). Foi observado que a maturação das sementes ocorreu gradativamente, com as cariopses destacando-se uma a uma, em espiguetas na forma de artículos. Dessa forma, apenas as sementes das extremidades das espiguetas encontravam-se maduras e viáveis, ocasionando baixa germinação quando contrastadas com sementes coletadas por varredura do solo.

Pelo teste de germinação realizado mensalmente, as sementes de capim-camalote armazenadas sob condição de câmara fria tiveram redução na porcentagem e no índice de velocidade de geminação à medida que se aumentou o período de armazenamento. Essa redução se deveu à condição de armazenamento $\left(7{ }^{\circ} \mathrm{C}, \mathrm{UR}\right.$ ar $\left.<20 \%\right)$, pois, nesse periodo, a porcentagem de sementes viáveis (dormentes) aumentou, enquanto a porcentagem de sementes inviáveis manteve-se praticamente constante (Tabela 10). Por outro lado, sob condições de laboratório, foi constatado comportamento oposto, ocorrendo incremento na porcentagem e no índice de velocidade de geminação, com diminuição na porcentagem de sementes viáveis em função do período de armazenamento. A partir de um mês de armazenamento, foi verificado que as sementes que se encontravam sob condição de laboratório apresentaram maior porcentagem e índice de
Tabela 9 - Valores médios de porcentagem de germinação (\%G) e índice de velocidade de germinação (IVG) de sementes de R. cochinchinensis recém-colhidas na planta e por varredura no solo

\begin{tabular}{|c|c|c|c|c|}
\hline \multirow{2}{*}{$\begin{array}{c}\text { Profundidade } \\
(\mathrm{cm})\end{array}$} & \multicolumn{2}{|c|}{ Na planta } & \multicolumn{2}{c|}{ Varredura } \\
\cline { 2 - 5 } & $\% \mathrm{G}^{\mathbf{1}^{\prime}}$ & $\mathrm{IVG}$ & $\mathrm{F} \mathrm{G}^{\mathbf{1}^{\prime}}$ & $\mathrm{IVG}$ \\
\hline 1 & 14 & 85 & 20 & 323 \\
\hline 2 & 6 & 30 & 34 & 230 \\
\hline 3 & 10 & 52 & 38 & 456 \\
\hline 4 & 6 & 32 & 20 & 220 \\
\hline 5 & 10 & 56 & 36 & 346 \\
\hline 6 & 10 & 54 & 32 & 242 \\
\hline 7 & 12 & 66 & 24 & 246 \\
\hline 8 & 10 & 57 & 36 & 402 \\
\hline 9 & 8 & 43 & 14 & 150 \\
\hline 10 & 8 & 46 & 16 & 194 \\
\hline Média & 9,4 & 52 & 27 & 272 \\
\hline Desvio-Padrão & 2,37 & 15,41 & 8,68 & 92,11 \\
\hline
\end{tabular}

1/ Valores transformados em arc sen $V_{\mathrm{x}}$

Tabela 10 - Porcentagem de germinação (\%G) e índice de velocidade de germinação (IVG) de sementes de $R$. cochinchinensis, em função do tempo de armazenamento sob condições de câmara fria $\left(7^{\circ} \mathrm{C}\right)$ e de laboratório, com porcentagens de sementes viáveis e inviáveis remanescentes do teste de germinação

\begin{tabular}{|c|c|c|c|c|}
\hline Mês & $\% \mathrm{G}$ & IVG & Viável (\%) & Inviável (\%) \\
\hline \multicolumn{5}{|c|}{ Condições de câmara fria } \\
\hline 0 & 29,6 & 297 & 41 & 24 \\
\hline 1 & 20,4 & 249 & 61 & 17 \\
\hline 2 & 21,2 & 256 & 65 & 13 \\
\hline 3 & 24,8 & 320 & 58 & 9 \\
\hline 4 & 24,0 & 302 & 64 & 11 \\
\hline 5 & 23,6 & 290 & 68 & 13 \\
\hline 6 & 12,0 & 153 & 73 & 17 \\
\hline 7 & 9,2 & 122 & 70 & 19 \\
\hline 8 & 10,4 & 134 & 74 & 18 \\
\hline 9 & 9,8 & 127 & 72 & 18 \\
\hline 10 & 8,9 & 120 & 75 & 16 \\
\hline 11 & 8,7 & 119 & 75 & 16 \\
\hline \multicolumn{5}{|c|}{ Condições de laboratório } \\
\hline 0 & 24,4 & 247 & 44 & 22 \\
\hline 1 & 41,5 & 547 & 41 & 15 \\
\hline 2 & 38,8 & 534 & 52 & 9 \\
\hline 3 & 38,0 & 541 & 61 & 8 \\
\hline 4 & 43,6 & 614 & 40 & 11 \\
\hline 5 & 47,2 & 667 & 38 & 13 \\
\hline 6 & 50,0 & 701 & 38 & 12 \\
\hline 7 & 54,4 & 767 & 36 & 13 \\
\hline 8 & 54,6 & 786 & 37 & 15 \\
\hline 9 & 52,9 & 754 & 35 & 13 \\
\hline 10 & 52,2 & 784 & 33 & 11 \\
\hline 11 & 53,7 & 758 & 33 & 9 \\
\hline
\end{tabular}


velocidade de germinação do que as sementes que se encontravam sob condições de câmara fria (Tabela 10). Esses resultados indicam que o frio pode ser um agente indutor de dormência em sementes de capim-camalote. Assim, sementes que se encontram em maiores profundidades no solo poderão persistir por um tempo mais prolongado e, consequentemente, resultar em futuras infestações, corroborando os dados de Bridgemohan et al. (1991), que constataram maior viabilidade de sementes de capim-camalote no solo a $20 \mathrm{~cm}$ de profundidade, e justificando plenamente a preocupação de Rojas et al. (1994) em prevenir a entrada de sementes dessa planta daninha no banco de sementes por meio do seu enterrio.

Estudos realizados com varias espécies de braquiárias (B. decumbens, B. plantaginea, $B$. ruziziensis e $B$. brizantha) apontaram que o armazenamento é recomendável na germinação de suas sementes (Câmara \& StacciariniSeraphin, 2002). Viera (1994), estudando a germinação de sementes de Brachiaria brizantha cultivar Marandu, concluiu que a porcentagem de germinação eleva-se com o tempo de armazenamento, atingindo 98,9\% entre 11 e 12 meses de armazenamento.

Pelos resultados obtidos, pode-se inferir que as sementes de capim-camalote têm elevado indice de velocidade de germinação, praticamente não apresentam dormência e não se mostram fotoblásticas. A deficiência hídrica já a partir de -0,2 MPa compromete a germinação das sementes, demonstrando que disponibilidade de água é indispensável para a germinação, sendo sua temperatura ideal de $25^{\circ} \mathrm{C}$. As sementes de capim-camalote coletadas na planta são inviáveis para o estudo de germinação, apresentando redução em sua porcentagem quando armazenadas sob condições de câmara fria e seca, demonstrando assim que o frio pode ser um agente indutor da dormência.

\section{LITERATURA CITADA}

ALLOUB, H. et al. Growth behavior of itchgrass (Rottboellia cochinchinensis) in Peninsular Malaysia. Weed Biol. Manag., v. 5, n. 1, p. 8-13, 2005.

ARÉVALO R. A.; BERTONCINI, E. I. Biologia e manejo de Rottboellia exaltata na cultura da cana-de-açúcar Saccharum spp.: análise do problema. Piracicaba: Estação Experimental de cana-de-açúcar- IAC, 1992. 42 p.
BIANCO, S.; BARBOSA JUNIOR, A. F.; PITELLI, R. A Crescimento e nutrição mineral de capim-camalote. Planta Daninha, v. 22, n. 3, p. 375-380, 2004

BRIDGEMOHAM, P.; BRATHWAITE, R. A. I.; MAC DAVI, C. R. Seed survival and patterns of seedling emergence studies of Rottboellia cochinchinensis Clayton in cultivated soils. Weed Res., v. 31, n. 5, p. 265-72, 1991

BRIDGEMOHAN, P. et al. The effects of Rottboellia cochinchinensis on the growth, development and yield of maize. Trop. Pest Manag., v. 38, n. 4, p. 400-407, 1992.

CÂMARA, H. H. L. L.; STACCIARINI-SERAPHIN, E. Germinação de sementes de Brachiaria brizantha $\mathrm{cv}$. Marandu sob diferentes períodos de armazenamento e tratamento hormonal. Pesq. Agropec. Trop., v. 32, n. 1, p. $21-28,2002$

CHIKOYE, D.; MANYONG, V. M.; EKELEME, F. Characteristics of speargrass (Imperata cylindrica) dominated fields in West Africa: Crops, soil properties, farmer perceptions and management strategies. Crop Protec., v. 19, n. 6, p. $481-487,2000$.

DANTAS, B. F. et al. Germinação de sementes de capimmarmelada (Brachiaria plantaginea (Link) Hitchc.) tratadas com ácido giberélico. R. Bras. Sem., v. 23, n. 2, p. 27-34, 2001.

DEUBER, R. Ciência das plantas daninhas; fundamentos. Jaboticabal: Funep, 1992. v.1. 431 p.

ETEJERE, E. O.; AJBOLA, I. O. Studies on seed germination and dormancy of Itchgrass (Rottboellia exaltata) Nig. J. Weed. Sci., v. 3, v. 1, p.19-28, 1991.

FAO. Memoria Taller Regional Manejo de la Maleza Caminadora Rottboellia cochinchinensis (Lour.) Clayton. Managua (Nicaragua). Rome: FAO/USDA, 1992. 23p.

FREITAS, R. R.; CARVALHO, D. A.; ALVARENGA, A. A. Quebra de dormência de capim-marmelada (Brachiaria plantaginea). R. Bras. Fisiol. Veg., v. 2, n. 2, p. 31-35, 1990

FREITAS, S. P. et. al. Controle químico de Rottboellia exaltata em cana-de-açúcar. Planta Daninha, v. 22, n. 3 , p. 461-466, 2004.

GUPTA, S. C. Seed dormancy studies in some Ocimum species and its control through chemical treatment. J. Medic. Aromatic Plant Sci., v. 24, n. 4, p. 957-960, 2002.

HALL, D. W.; PATTERSON, D. T. Itchgrass: Stop the trains. Weed Technol., v. 6, n. 1, p. 239-241, 1992.

HERNÁNDEZ, R.; SOTO, A. Influencia del déficit hídrico en la germinación de Rottboellia exaltata bajo sequía simulada. Agron. Costarricense, v. 14, n. 2, p. 135-140, 1990. 
HOLM, L. G. et al. The world's worst weeds. Distribution and biology. Honolulu: University Press of Hawaii, 1977. $609 \mathrm{p}$.

ISHIMINE, Y. et al. Physiological and ecological characteristics of sugarcane field weeds in the Ryukyu Island. Effect of shade on growth and seed production of (Rottboellia exaltata and Solanum alatum). Weed. Res., v. 33, n. 2 , p. 114-121, 1988.

KHAN, A. A. The physiology and biochemistry of seed dormancy and germination. Amsterdam: Elsevier/NorthHolland, 1977. $447 \mathrm{p}$

LORENZI, H. Plantas daninhas do Brasil: terrestres, aquáticas parasitas e tóxicas. 3.ed. Nova Odessa: Plantarum, 2000. 608 p.

LOUBSER, W. A.; ROBERT, E. Dormancy - breaking treatments for subtropical grass seed. In: INTERNATIONAL SEED TESTING CONGRESS, 33., 1992, Buenos Aires. Abstracts... Buenos Aires: ISTA, 1992. p. 80.

LULA, A. A. et al. Estudos de agentes químicos na quebra da dormência de sementes de Paspalum paniculatum L. Ci. Agrotec., v. 24, n. 2, p. 358-366, 2000

MARTINS, L.; SILVA, W. R. Comportamento da dormência em sementes de braquiária submetidas a tratamentos térmicos e químicos. Pesq. Agropec. Bras., v. 36, n. 7, p. 997-1003, 2001.

MESCHEDE, D. K. et al. Tratamentos para superação da dormência das sementes de capim- braquiária cultivar Marandu. R. Bras. Sementes, v. 26, n. 2, p. 76-81, 2004

PATTERSON, D. T. et al. Temperature responses and potential distribution of itchgrass (Rottboellia exaltata) in the United States. Weed Sci., v.27, n. 1, p.77-82, 1979.

POPINIGIS, F. Fisiologia da semente. 2.ed. Brasília: 1985. $289 \mathrm{p}$

PUTNAM, A. R.; TANG, C. S. The science of allelopathy New York: John Wiley \& Sons, 1986. 316 p.

ROBERTS, E. H. Dormancy: A factor affecting seed survival in the soil. In: ROBERTS, E. H. (Ed.). Viability of seeds Syracuse: Syracuse University Press, 1972. p. 321-359.
ROJAS, C. E.; DE LA CRUZ, R.; MERAYO, A. La profundidad y duración en el suelo de la semilla de caminadora (Rottboellia cochinchinensis (Lour.) Clayton) y su efecto sobre la viabilidad y persistencia en el trópico seco. Manejo Integrado de Plaga, v.32, p. 25-29, 1994.

SALVADOR, F. L. et al. Efeito da luz e da quebra de dormência na germinação de sementes de espécies de plantas daninhas. Planta Daninha, v. 25, n. 2, p. 303-308, 2007.

SARUHAN, N.; KADIOGLU, A.; DURMUS, N. Alleviation of seed dormancy in Plantago major. Israel $\mathbf{J}$. Plant Sci., v. 50, n. 3, p. 177-179, 2002.

SCHIMIDT, R. L. Seed dormancy in Panicum maximum Jacq. Trop. Agric., v. 56, n. 3, p. 233-239, 1979.

SHARMA, D.; ZELAYA, O. Competition and control of itchgrass (Rottboellia exaltata) in maize (Zea mays). Inter. J. Pest Manag.., v. 32, n. 2, p.101-104, 1986.

SMITH, M. C. et al. Integrated management of itchgrass in a corn cropping system: Modelling the effect of control tactics. Weed Sci., v.49, n. 1, p. 123-134, 2001.

TOLEDO, F. F.; CHAMMA, H. M. C. P.; NOVEMBRE, A. D. L. C. Germinação de sementes de Panicum maximum Jacq. pré-tratadas com ácido sulfúrico. Sci. Agríc., v. 52, n. 1, p. $20-24,1995$

TOOLE, E. H. et al. Physiology of seed germination. Ann. Rev. Plant Physiol., v. 7, p. 299-324, 1956.

TUCUCH, F. M. Estudio de la fenología y características reproductivas del zacate peludo (Rottboellia cochinchinensis) en el estado de Campeche. México: ASOMECIMA, 1991. p. 7-10 (Series Técnicas de ASOMECIMA, Asociación Mexicana de la Ciencia de la Maleza, 1)

USBERTI, R. Nova metodologia para o teste de germinação de sementes de capim-colonião. Casa Agric., n. 1, p. 12-16, 1981.

VIEIRA, R. D.; CARVALHO, N. M. Testes de vigor em sementes. Jaboticabal: UNESP/FUNEP, 1994. 164 p. 